\section{Use of Unneutralized Hydrolysates in Paper Chromatography of Sugars}

IN preparing hydrolysates of polysaccharides for paper chromatography, it has always been considered necessary to neutralize the sulphuric acid with barium carbonate before applying the solution to the paper, as the acid causes disturbing stains. Indeed, when using an ammoniacal silver spray, white stains appear at the place where the spots of glucose and galactose should be; but the flow of the sugars does not seem to be disturbed.

It occurred to me that an acid spray as, for example, aniline phthalate or phosphate, would not be impeded by the acid of the hydrolysate. In order to examine this, I carried out some experiments with (1) a simple solution of some sugars in $N$ sulphuric acid; (2) a polysaccharide hydrolysate.

From both solutions chromatograms were made without previous neutralization, using benzenebutanol-pyridine-water $(1-5-3-3)$ as a solvent and aniline phosphate as a spray. All sugars and uronic acid showed up clearly at their usual places, whereas no stains of the acid could be detected.

Quantitative determinations were also made on both solutions before and after neutrelization, using rhamnose as a reference sugar. The sugar zones were eluted under reflux and the sugars estimated colorimetrically ${ }^{1}$.

The results were as follows :

Solution of Sugars IN $N$ Sulphurtc Acid mgm. added mgm. found :

$\begin{array}{lccc} & & \text { in acid solution } & \text { in neutral solution } \\ \text { Galactose } & 10 & 10 \cdot 6 & 10 \cdot 4 \\ \text { Glucose } & 10 & 9 \cdot 6 & 9 \cdot 4 \\ \text { Arabinose } & 20 & 20 \cdot 2 & 19 \cdot 8 \\ \text { Xylose } & 40 & 39.8 & 39 \cdot 0\end{array}$

\begin{tabular}{|c|c|c|}
\hline \multicolumn{3}{|c|}{ POIYSACCHARIDE HYIROLYSATE } \\
\hline & Acid hydrolysate & Neutralized hydrolysate \\
\hline Galacturonic acid & $2 \cdot 6$ per cent & $2 \cdot 8$ per cent \\
\hline Galactose & $1.2 \quad "$ & $1 \cdot 5^{-}$ \\
\hline (xlucose & $3 \cdot 8 \quad$ & $3 \cdot 6$ \\
\hline Arabinose & $8 \cdot 7$ & $8 \cdot 6$ \\
\hline Xylose & $67 \cdot 1$ & $65 \cdot 6$ \\
\hline
\end{tabular}

The results obtained show clearly that it is not necessary to neutralize the hydrolysates of polysaccharides before applying them to paper chromatograms, provided an aniline phosphate or phthalate spray is used.

Blanche D. E. Gaillard

Laboratory of Animal Physiology,

Agricultural University College,

Wageningen.

Nov. 14.

1 Somogyi, M., J. Biol. Chem., 195, 19 (1952). Nelson, N., J. Biol. Chem., 153, 375 (1944).

\section{Detection of some Precursors of} Adrenaline by Paper Chromatography

DurING studies on the biosynthesis of adrenaline, both para- and meta-hydroxyphenylethanolamine have been found to form noradrenaline following ultraviolet irradiation in the presence of air ${ }^{1}$. Whereas the para compound has been identificd in Octopus vulgaris ${ }^{2}$, the meta compound has not hitherto been found occurring naturally. Their detection in biological materials is a major problem. With the aid of paper chromatography, using a solvent of butanol (4 vol.), glacial acetic acid (1 vol.) and water (5 vol.), we have found that the meta compound exhibits an intense violet fluorescence under ultra- violet light when the developing agent is a mixture of 9 vol. of a solution of either potassium ferricyanide or dichromate $(0.66$ per cent) and 1 vol. of formalde hyde (40 per cent), followed by exposure to heat $\left(100^{\circ}\right.$ C.) for $5 \mathrm{~min}$. As little as $0.5 \mu \mathrm{gm}$. $\left(R_{F}\right.$ value 0.56 ) can be identified by this test. Development with the $p$-nitraniline reagent ${ }^{3}$ results in a dark red spot (similar to that produced with the para compound), but this test is only sensitive to $5 \mathrm{\mu gm}$.

Using the mixture of ferricyanide (but not dichromate) and formaldehyde as developer, followed by heating at $100^{\circ} \mathrm{C}$., we have now found that noradrenaline $\left(R_{F}\right.$ value 0.28$)$ exhibits a turquoise fluorescence in ultra-violet light, and as little as $0.2 \mu \mathrm{gm}$. can easily be detected on chromatography paper. Under similar conditions, adrenaline $\left(R_{F}\right.$ value 0.36 ) shows a yellow-green fluorescence if a minimum of $0.4 \mu \mathrm{gm}$. is present. Adrenaline in simple alkaline solution develops a transient green fluorescence, and Gaddum and Schild ${ }^{4}$ in 1934 directed attention to the specificity of this reaction at low concentrations. Many substances chemically related to adrenaline (for example, noradrenaline and $\mathrm{di}$ hydroxyphenylalanine) produce the same green fluorescence only in much stronger concentrations. For example, West ${ }^{5}$ found that noradrenaline is about thirty-three times less active than adrenaline in this test.

Using chromatography and the new developer (ferricyanide and formaldehyde mixture), noradrenaline is twice as active as adrenaline, so that very small amounts of noradrenaline can be detected in the presence of much larger quantities of adrenaline. Under similar conditions, both hydroxytyramine $\left(R_{F}\right.$ value $\left.0 \cdot 39\right)$ and dihydroxyphenylalanine $\left(R_{F}\right.$ value $0 \cdot 19$ ) show a yellow fluorescence if a minimum of $1.0 \mu \mathrm{gm}$. is present.

D. M. SHEPHERD

G. B. West

Department of Pharmacology and Therapeutics, University of St. Andrews Medical School, Dundee. Jan. 15.

${ }^{1}$ Shepherd, D. M., and West, G. B., J. Pharm. Pharmacol., 4, 6r' (1952)

2 Erspamer, V., Nature, 169, 375 (1952).

${ }^{3}$ Wickström, A., and Salvesen, B., J. Pharm. Pharmacol., 4, 631 (1952).

${ }^{4}$ Gaddum, J. H., and Schild, H., J. Physiol., 80, 91' (1934).

West, G. B., J. Physiol., 106, 418 (1947).

\section{Occurrence of Hydroxylamine in Lake Waters as an Intermediate in Bacterial Reduction of Nitrate}

THE occurrence of hydroxylamine as an intermediate of the enzymatic reduction $\mathrm{NO}_{3}{ }^{-} \rightarrow \mathrm{NH}_{3}$ or oxidation $\mathrm{NH}_{3} \rightarrow \mathrm{NO}_{3}^{-}$has recently interested many biochemists ${ }^{1}$. Thus certain authors have been able to confirm the formation of this compound in the process of the oxidation or reduction of nitrogen compounds ${ }^{2,3}$.

The following observations (see table) show that hydroxylamine occurs in the water of Kizaki-ko, a. mountain lake in Central Japan, mesotrophic in nature and with a maximum depth of $29 \cdot 5 \mathrm{~m}$. In this lake, in the middle of autumn, there appears every year a very pronounced stratification of inorganic nitrogen compounds. At the beginning of summer, the nitrate increases with increasing depth, and as the period of stagnation proceeds, the oxygen content decreases in the bottom layers. In these layers, the activities of nitrate-reducing bacteria 